\title{
Mobile Social Network Sites as innovative pedagogical tools: factors and mechanism affecting students' continuance intention on use
}

\author{
R.-B. Wang • C.-T. Du
}

Received: 11 August 2014/Revised: 29 September 2014/Accepted: 30 September 2014/

Published online: 16 October 2014

(C) Beijing Normal University 2014

\begin{abstract}
Mobile Social Network Site (MSNS) is introduced into teaching and learning as a kind of innovative pedagogical tool, called MSNS-based ubiquitous learning, which allows students to learn at anytime and anywhere. Continuous use is the success of an innovative tool. Nevertheless, several previous studies have indicated factors and mechanism affecting students' continuance intention in the context of MSNS-based ubiquitous learning. In this study, a behavioral model based on "cognitionaffect-conation" framework is proposed to interpret factors' impacts on students' continuance intention, along with the clarification of the mechanism. Both qualitative (focus group interview) and quantitative (survey) methods are employed in this study. Confirmatory factor analysis, hierarchical confirmatory factor analysis, and full model of structural equation modeling are applied to validate the research model and hypotheses. Results reveal that perceived convenient function, teachers' participation, interaction expansion, course content fit, and information richness are reflective constructs to the perceived quality of a MSNS-based pedagogy, which put impacts on students' continuance intention through perceived value and users' satisfaction, perceived value mediates the impact of perceived quality of an MSNS on satisfaction, and satisfaction also mediates the impact of perceived value on continuance intention.
\end{abstract}

Keywords Mobile Social Network Sites · Continuance intention · Perceived quality $\cdot$ Perceived value $\cdot$ Satisfaction $\cdot$ Pedagogical tools

\section{Introduction}

In the past few decades, systems or applications based on information and communication technology (ICT) have been widely utilized as innovative tools in

R.-B. Wang $(\varangle) \cdot$ C.-T. Du

School of Computer Science, North China University of Technology, Beijing, China

e-mail: robin945@gmail.com 
all kinds of social lives, including e-learning. Continuous use, also understood as users' retention, is important to the success of innovative tools and systems (Bhattacherjee 2001; Chang et al. 2013; Lee 2010; Liang et al. 2013; Limayem and Cheung 2008; Lin 2011; Lin et al. 2011; Lin and Wang 2012; Shin et al. 2011).

Social Network Sites (SNSs), such as Facebook and Weibo, have boomed in recent years. As innovative internet-based tools for social interaction, they bridge online and offline social networks (Ellison 2007). Mobile devices and wireless technology facilitate the use of SNSs in a ubiquitous way, to this extend, they are Mobile Social Network Sites (MSNSs). MSNSs can substantially lower the barriers to social discourse by minimizing unfamiliarity, which could revolutionize human social interaction (Beach et al. 2008). With advantages of accessing at anytime and anywhere, MSNSs are employed as innovative pedagogical tools in e-learning, which brings "anywhere and anytime learning" or even "context-aware learning" to learners, called ubiquitous learning (u-learning) (Hwang et al. 2008; Ogata et al. 2011).

Many researchers focused their interest on MSNS users' retention in the context of social interactions. However, pedagogical utilizing is not the same as daily social interaction after all. Especially, influencing factors are different in different utilizing contexts. Existing researches on conventional utilizing for daily social interaction cannot explain learners' continuous behavior well. Consequently, it is crucial to find out factors to learners' continuance intention on MSN-based pedagogy and clarify the affecting mechanism in the context of MSNS-based u-learning.

The first research question is what factors will affect students' perception on the quality of a MSNS in u-learning. Mobile application utilizing is taken as the use of mobile services from the perspective of Human-Computer interaction (Becker et al. 2012; Liang et al. 2013), accordingly, perceptions on mobile applications utilizing can be measured by SERVQUAL (Parasuraman et al. 1988) or modified SERVQUAL, which is designed for service quality measurement. However, the context of a business service use is different from that of a pedagogical tool utilizing, and factors affecting learners' perception on service quality are different from those of business service. Therefore, finding out these factors, constructing, and validating the measurement model deserve further exploration.

The second research question is whether or not a higher-order factor can indicate learners' perception on a MSN-based pedagogy. Learners' continuance use is affected not only by service quality, but also by other factors. Nevertheless, service quality bears multiple constructs (factors) to measure different aspects of a service. Including these constructs into the continuance behavioral model directly may cause problems such as over complexity. Although some research simplified its model directly, further validation is necessary to a rigorous scientific research. Wang et al. provides an approach for simplification in Human-Computer interaction research (Wang et al. 2014). Accordingly, it is essential to examine the higher-order factor in the context of MSNS-based pedagogy utilizing.

"Cognition-affect-conation" framework is effective in predicting users' behavior (Bagozzi 1992) and it is adopted in pervious service and behavioral researches (Kettinger et al. 2009; Zhao et al. 2012). Nevertheless, the validation on effectiveness of this framework in u-learning behavior is still unexplored. Thus, 
the third research question is whether or not the "cognition-affect-conation" mode is impactful in explaining learners' continuance use in the context of MSNS-based uleaning.

There are three elements in the "cognition-affect-conation" framework. According to the framework, the conation is not affected directly by cognition but mediated by affect. However, the mechanism of users' continuance behavior in the context of MSNS-based u-learning is not clarified yet. Therefore, clarifying the mediating mechanism is an important issue in the research of users' continuance behavior. Consequently, we put forward the fourth research question: what factors will mediate the effect of perceived quality on users' continuance intention and what is the mechanism?

In order to answer the above research questions, the study implemented a focus group interview with eight college students to find out their perceptions on a MSNSbased pedagogical tool in the context of u-learning. Furthermore, to validate the proposed model, a survey was conducted on the students from a Chinese university.

The results will provide implications for the improvement of the innovative pedagogical tools utilization. The rest parts of this paper are organized as follows: literature review will be provided in next section. In section three, the research methodology is presented. The fourth section will present the results of data analysis. Discussion and conclusion will be presented in the last section.

\section{Literature review}

Ubiquitous learning is a new concept put forward in recent years. Progress in mobile and sensor technologies has lead to the new development of learning environments and consequently led to the evolution of teaching and learning mode. Hwang et al. defined the basic criteria of u-learning environment and proposed various models for conducting u-learning (Hwang et al. 2008). Especially, the utilization of mobile devices and applications promoted the development of ubiquitous learning.

Ogata et al. proposed a ubiquitous learning log system with the aim of sharing and reusing past learning experiences with the application in undergraduate English course (Ogata et al. 2011). Hwang et al. presented a ubiquitous learning system to enhancing students' motivation and learning performance of scientific inquiry activities (Hwang et al. 2012). A project for advanced ubiquitous learning was illustrated and effectiveness of the Mindtool-assisted ubiquitous learning approach was validated in their research (Hwang et al. 2014). The literatures mentioned put their attention on the design and utilizing of novel u-learning modes and approaches. However, several previous researches put their attention on another important issue, which is the continuance use of an innovative u-learning pedagogy.

Users' continuance behavior has aroused researchers' attention more than 10 years ago. Bhattacherjee proposed and validated a post-acceptance model of information systems (IS) continuance (Bhattacherjee 2001). Chui et al. explored users' continuance decision based on a decomposed expectancy disconfirmation theory (EDT) model (Chiu et al. 2005). Limayem and Cheung revealed the mediating effect from students' IS habit in the context of Blackboard use (Limayem 
and Cheung 2008). Chiu and Wang introduced components of subjective task value into a model to extend the Unified Theory of Acceptance and Use of Technology (UTAUT) for studying learners' continuance intentions in Web-based learning (Chiu and Wang 2008). Kettinger et al. provided a comprehensive model that synthesized customer satisfaction and dissatisfaction models to predict the behavioral intentions of customers to reuse IS services through the perspective of service reuse (Kettinger et al. 2009). Lee synthesized the expectation-confirmation model, the technology acceptance model (TAM), the theory of planned behavior, and the flow theory into a behavioral model to predict users' intentions to continue using e-learning (Lee 2010). Venkatesh et al. presented a two-stage model based on expectation confirmation theory to explain IS continuance, in which they included predictors in UTAUT and grounded the model in the context of sensitive information transmission.(Venkatesh et al. 2011). Lin et al. developed a model and validated the key drivers of users' continuance intention of e-learning based on negative critical incidents standpoints (Lin et al. 2011). Shin et al. examined factors influencing users' continuous intention on smart phones as a u-leaning tool (Shin et al. 2011). Lin put his emphasis on the moderating effects of e-learning experience on the relationships among determinants of the e-learning continuance intention of use (Lin 2011). Lin and Wang investigated the relation between perceived fit and system factors that can motivate learners' continuance intention on an e-learning system use in blended learning instruction (Lin and Wang 2012). Chang et al. explored determinants of mobile English learning systems continuance intention from the perspective of college students' intrinsic and extrinsic motivation based on TMA (Chang et al. 2013). Liang et al. explored mobile services continuance intention with their focus on contextual factors (Liang et al. 2013). Terzis et al. explained IS continuance acceptance in the context of computer-based assessment by measuring users' expectation and perception (Terzis et al. 2013).

On the one hand, the ICT-based tools studied in existing literatures have transformed from computer-based information systems (Bhattacherjee 2001) or computer-delivered services(Kettinger et al. 2009) to web-based systems (Chiu et al. 2005; Chiu and Wang 2008; Limayem and Cheung 2008), PDA or smart phones (Shin et al. 2011), and mobile services(Liang et al. 2013; Liu et al. 2010; Ng and Kwahk 2010), which revealed that more and more researchers are focusing on utilizing behavior of mobile devices, applications, or services. However, several previous studies have indicated students' continuance behavioral intention in the context of MSNS-based u-learning. In particular, there is still lack of study conducted from the perspective of pedagogical tools use. Therefore, pedagogical context-aware factors in u-learning deserve further attention.

On the other hand, SNS is different from personal computer-based systems or applications with its distinctive characteristic of social interaction, which put users in an open communication. Furthermore, mobile technology makes it possible for users to communicate ubiquitously by MSNS-based tools as they need. Nevertheless, many studies focused on system-related or device-related factors and their impacts on continuance intention. Seldom study follows the interest on factors reflected by the distinctive characteristics of mobile access and social interaction. Accordingly, mobile access and social interaction are worth giving more attentions. 


\section{Research methodology}

MSNSs provide mobile services to the public for different usages in their social life. And they have been introduced into learning and teaching as pedagogical tools in recent years. In this study, there are two parts of work in the section of research methodology: the first part is focus group interview, which aims at identifying students' perception on MSNS-based pedagogical tools, then the measurement model of perceived quality will be constructed, along with the second-order factor model; the second part is structural model and research hypothesis, with objects of indicating factors and mechanism to continuance intention, follows the expatiation of the survey sample and data collection.

\section{Focus group interview}

In order to identify constructs of students' perceived quality on MSNS-based pedagogical tools, eight undergraduate students from a Chinese university were enrolled in a focus group interview. They attended the interview voluntarily. The eight interviewees were suggested using Sina Weibo, a popular SNS in China, on their smart phones during eight successive weeks in a course to investigate issues of MSNS-based pedagogical tools use in u-learning.

By utilizing Weibo, interviewees were able to contact with their instructor, conduct a discussion with others not just limited to the students registered in the course, get up-to-date course materials or information, contribute their information materials to the social network groups, and make new friends who have similar interest all around the world. All interview subjects participated in a 30-min interview in which they expressed their opinions about the MSNS-based pedagogical tool utilizing on the foundation of their perception.

All interview scripts were analyzed for identifying critical factors affecting learners' perception on a MSNS-based pedagogical tool. Subjects put forward the worthiness of utilizing Weibo in u-learning on the ground of:

(1) Perceived convenient function: "By using Weibo on my smart phone, I can follow others, post information, and contact with each other very conveniently."

(2) Teacher's participation: "The course instructor often updates his information and responses to students' posted information."

(3) Interaction expansion: "By utilizing Weibo on my smart phone, I expand my interactions with others substantially, my friends are not only my classmates, but also net friends out of my university."

(4) Course content fit: "On Weibo, I can find information related to my course in learning, and some has good fit to my course content."

(5) Information richness: "On Weibo, I can find massive information related to different aspects of social life."

As two sides of a coin, there were some complaints concerned:

(1) My continuance utilizing of Weibo as a pedagogical tool largely depends on my instructor's participation and guidance, if he does not often update the 
information on Weibo, I probably lose my interest on using Weibo as a ulearning tool, but maybe I will continuously use it as a social interaction tool.

(2) Each piece of information posted on Weibo is limited to less than 140 words, which is not fit for complex expression.

(3) There is too much information on Weibo, for me, the difficulty is how to retrieve the useful ones from massive information.

Measurement model of MSNS-based pedagogical tools perception

On the foundation of interview script analysis, the author proposed a measurement model of MSNS-based pedagogical tools perception. Constructing a measurement model to acquire users' perception is not a brand new idea, SERVQUAL is used to measure customers' perception on service quality (Parasuraman et al. 1988). Service quality has been studied well in the field of marketing, and the measurement scale was used in different industries. However, the context of pedagogical tools utilizing is different from that of service delivery in commerce. It is necessary to construct a measurement model being fit to the context of pedagogical tools utilizing. Figure 1

Fig. 1 The measurement model of MSNS-based pedagogical tools perception

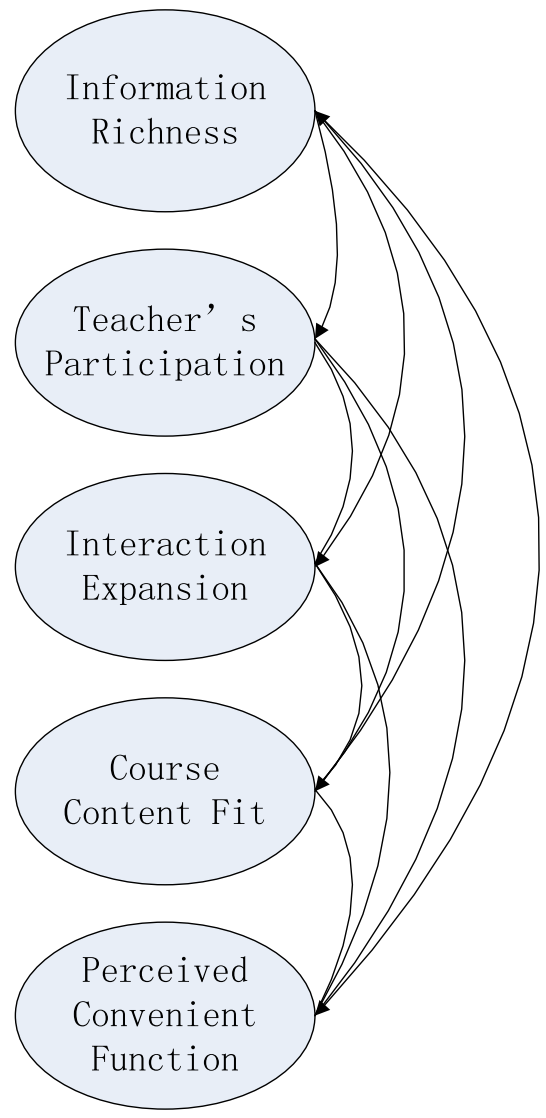


depicts constructs of the model; they are Information Richness, Teacher's Participation, Interaction Expansion, Course Content Fit, and Perceived Convenient Function, which are derived from focus group interview script analysis. And the reliability and validity of the model will be discussed in the section of data analysis. As a multiple scale, students' perception on MSNS-based pedagogical tools is an issue deserving further attention on model simplicity, which will also be discussed in the section of data analysis.

Second-order factor model of MSNS-based pedagogical tools perception

As illustrated in Fig. 1, perceived quality of a MSNS is the one with multiple constructs. If the multi-construct model is introduced into the structural model directly, it will possibly lead to over complexity and even lead to unacceptable fit results. Therefore, simplifying the measurement model of MSNS-based pedagogical tools perception is necessary. According to the research of Wang et al., if a multiconstruct measurement model can be simplified into a higher-order factor model, then the higher-order factor can be introduced into the structural model as a variable with original constructs being packed as reflective items (Wang et al. 2014). Based

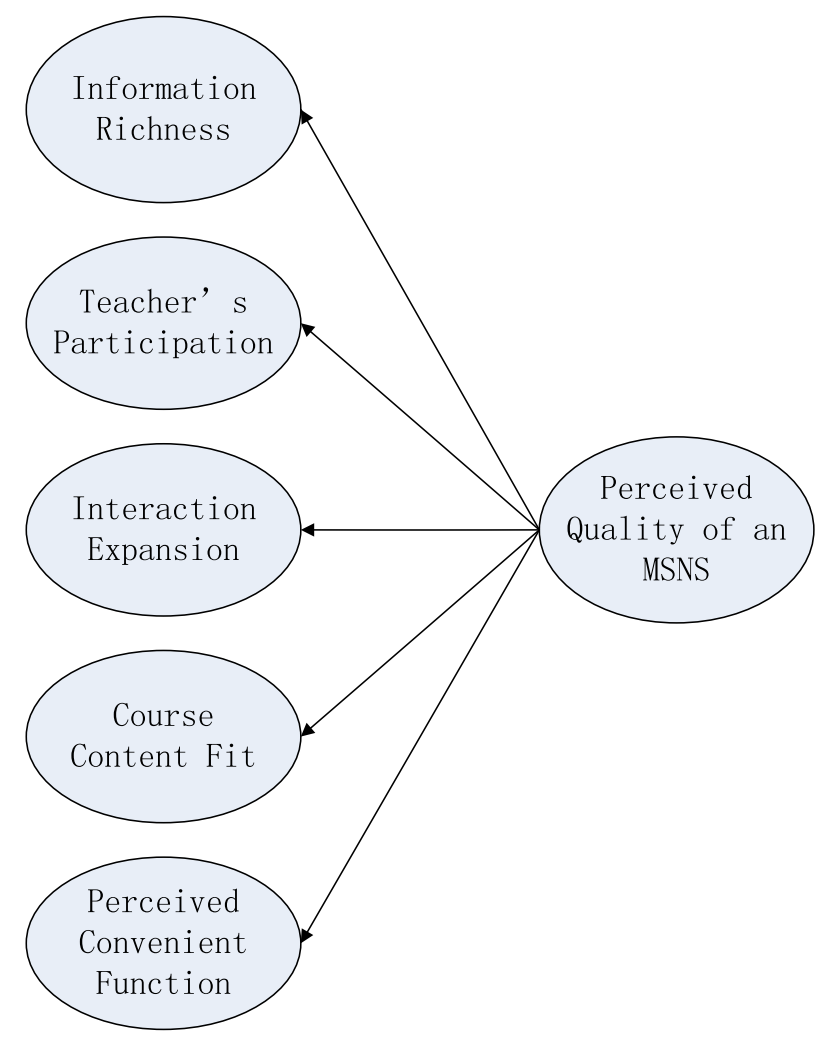

Fig. 2 The second-order factor model of MSNS-based pedagogical tools perception 
on the analysis above, a second-order factor model for MSNS perception is proposed as shown in Fig. 2.

If the second-order can be validated, then it can be introduced into the structural model as a single-construct latent variable, which will reduce model complexity substantially. In the section of data analysis, the measurement model and the second-order model will be examined first. Only when the second-order factor model is validated with acceptable reliability and validity, the simplified research model can be tested.

\section{Research model and hypotheses}

The formation of students' continuance intention is a complex psychological process, which is affected not only by students' perception on MSNS utilizing, but also by affective factors in the procedure of use. Perceived quality is the result of psychological response to the experiences of a MSNS utilizing. In some literatures, perceived ease of use in TAM (Davis 1989) was taken as a kind of perception, however, perceived ease of use is the perception on technology use only, it cannot cover all the context-aware factors in u-learning. Therefore, a variable named as 'perceived quality of an MSNS' is proposed, which is based on the analysis of the focus group interview.

Besides utilizing perception, other important variables impacting users' continuance intention in existing literatures include satisfaction (Bhattacherjee 2001; Chiu et al. 2005; Kettinger et al. 2009; Lee 2010; Limayem and Cheung 2008; Lin et al. 2011; Lin and Wang 2012; Ng and Kwahk 2010; Shin et al. 2011; Venkatesh et al. 2011), and perceived value (Kettinger et al. 2009; Ng and Kwahk 2010) or perceived usefulness(Bhattacherjee 2001; Chang et al. 2013a, 2013b; Lee 2010; Limayem and Cheung 2008; Lin et al. 2011; Lin and Wang 2012; Shin et al. 2011; Terzis et al. 2013; Venkatesh et al. 2011).

Impacts on users' continuance intention from satisfaction have been validated in many literatures. Satisfaction can be considered as the result of evaluative (cognitive), emotion-based, or both (Oliver 2010). Therefore, satisfaction is added into the model. Compared to perceived usefulness, perceived value is less studied in existing literatures. Perceived usefulness stands for users' psychological response to technology use only. In the context of a MSNS-based pedagogical tool utilizing, the use of a MSNS is the application of an innovative pedagogy, but not just a tool with advanced technology. To this extend, MSNS utilizing is a kind of service delivery, perceived value takes a better fit from this perspective. Consequently, perceived value is taken as another important independent variable.

Based on the analysis above, a research model following the "cognition-affectconation" framework (Bagozzi 1992) is proposed. The independant variables are perceived quality of a MSNS, perceived value, and students' satisfaction; they will put possible impacts on students' continuance intention, as depicted in Fig. 3.

Students' perception on the quality of a MSNS is a process of cognition formation. In the context of this study, the use of MSNS is a voluntary behavior, students need to learn how to use the innovative tool and spend time in u-leaning, which is a kind of cost sacrifice, though they do not pay for it. From the perspective 


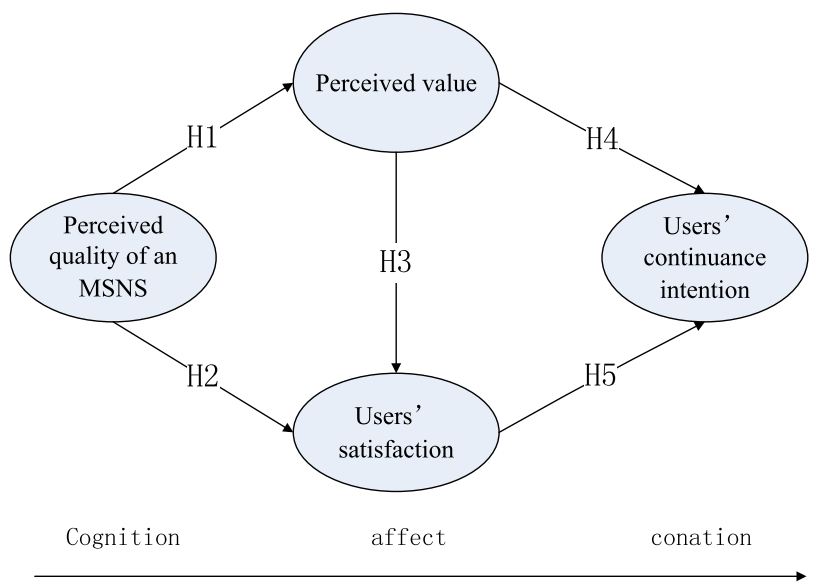

Fig. 3 The research model

of service delivery, students will get possible benefits from the use of a MSNS in uleaning. Consequently, perceived quality of a MSNS probably brings service value to students who use it. Therefore, a hypothesis is proposed as following:

Hypothesis 1 Students' perceived quality of a MSNS will positively affect their perceived value.

Perceived quality affects students' satisfaction positively, which has been validated in some literatures (Chiu et al. 2007; Lu and Chiou 2010; Zhao et al. 2012). What concerned in this study is whether or not perceived MSNS quality will put a positive effect on satisfaction in the context of u-learning, hence, the hypothesis is put forward as follows:

Hypothesis 2 Students' perceived quality of a MSNS will positively affect their satisfaction.

In the context of voluntary use of u-learning, the affect is specified as perceived value and satisfaction. And perceived value, also understood as perceived usefulness in some researches, put positive impact on satisfaction, which has been validated in some literatures (Kettinger et al. 2009; Limayem and Cheung 2008; Lin and Wang 2012; Shin et al. 2011). However, the relation between perceived value and users' satisfaction still needs to be examined in the context of u-learning with MSNS use. Accordingly, following hypothesis is proposed:

Hypothesis 3 Students' perceived value will positively affect their satisfaction.

It has been validated that perceived value or perceived usefulness put a positive impact on users' continuance intention (Chang et al. 2013a, b; Kettinger et al. 2009; Lee 2010; Lin et al. 2011; Lin and Wang 2012). Although no monetary cost is paid when students utilize MSNSs in u-learning, they still pay for it, such as time and efforts on learning how to use an MSNS, which probably will bring cognitive benefits to students. To this extend, perceived value will put effect on continuance intention. However, it needs to be validated in the context of MSNS use u-leaning. Accordingly, another hypothesis is put forward as following: 
Hypothesis 4 Students' perceived value will positively affect their continuance intention.

Users' satisfaction has been theorized and validated as an important antecedent to users' continuance intention in some existing literatures (Kettinger et al. 2009; Lee 2010; Limayem and Cheung 2008; Lin 2011; Lin et al. 2011; Lin and Wang 2012; Shin et al. 2011). These literatures provided adequate support for the relation of satisfaction to continuance intention, however, the situation in the context of MSNS use u-leaning deserves further examination. Hence, the last hypothesis is proposed as following:

Hypothesis 5 Students' satisfaction will positively affect their continuance intention.

Research context and survey sample

Smart phones are very popular in campus, and many SNSs can be accessed through Smart phones easily. Sina Weibo, a well-known SNS in China, which is similar to twitter, was introduced into course teaching as an innovative pedagogical tool in the study. Students from five classrooms of three computer courses in a Chinese university were invited to take the participation. The instructor can post messages related to courses, launch a discussion, answer questions, and release course notices. Students can follow the message posted, launch a topic related to the course learning, and of course, they can make friends on the MSNS. More importantly, many other users of Sina Weibo who are interested in the topic can attend the interactions, which distinctively differed from traditional classroom discussion or close style e-learning interactions. All students made the participation of MSNSbased u-leaning voluntarily.

\section{Measurement and data collection}

There were four constructs measured in the research model: perceived quality of a MSNS, students' satisfaction, perceived value, and users' continuance intention. The measurement items of perceived quality of a MSNS are based on the focus group interview script analysis. Measurement items of perceived value are adapted from items in existing literatures (Chiu et al. 2005; Kettinger et al. 2009; $\mathrm{Ng}$ and Kwahk 2010), items of satisfaction are adapted from satisfaction related literatures (Bhattacherjee 2001; Limayem and Cheung 2008; Lin and Wang 2012; Venkatesh et al. 2011; Zhao et al. 2012), and items of continuance intention are adapted from continuance behavioral researches (Bhattacherjee 2001; Chang et al. 2013; $\mathrm{Ng}$ and Kwahk 2010; Shin et al. 2011; Terzis et al. 2013; Venkatesh et al. 2011). The Appendix lists the scale items, see Table 5. All constructs were measured by multiitem scales with nine point Likert-type. All constructs got acceptable reliability and validity in the pilot test. The reliability and validity of all measurement items in the formal survey will be examined in the section of data analysis.

A pilot test was conducted in the 8th week of a semester with the aim of validity and reliability test. The survey was conducted in the 10th week; students completed 
their answer on the internet through an electronic questionnaire, which is anonymous and self-administered. The survey was distributed to 247 students and 212 returned their answer, with an $85.8 \%$ response rate. Five of them did not complete the questionnaire and four were determined not serious to the questionnaire, therefore there were 203 responses left for the final analysis.

\section{Data analysis}

Reliability and validity

To verify the reliability and validity of the constructs, Cronbach's $\alpha$ is employed, and composite reliability is used to assess reliability of each measure. The factor loadings of each item on corresponding constructs are observed from the confirmatory factor analysis to assess the measurement model. And average variance extracted is examined as well. Data are listed in Table 1.

Table 1 Reliability and validity

\begin{tabular}{|c|c|c|c|c|c|}
\hline \multirow{2}{*}{$\begin{array}{l}\text { Latent variables } \\
\text { Perceived convenient function }\end{array}$} & \multicolumn{2}{|c|}{ Factor loading } & \multirow{2}{*}{$\begin{array}{l}\text { Cronbach's } \alpha \\
0.795\end{array}$} & \multirow{2}{*}{$\begin{array}{l}\begin{array}{l}\text { Average variance } \\
\text { extracted (AVE) }\end{array} \\
0.5651\end{array}$} & \multirow{2}{*}{$\begin{array}{l}\begin{array}{l}\text { Composite } \\
\text { reliability }\end{array} \\
0.7951\end{array}$} \\
\hline & PCF1 & 0.68 & & & \\
\hline & PCF2 & 0.80 & & & \\
\hline & PCF3 & 0.77 & & & \\
\hline \multirow[t]{3}{*}{ Teachers' participation } & TP1 & 0.72 & 0.759 & 0.5227 & 0.7652 \\
\hline & $\mathrm{TP} 2$ & 0.80 & & & \\
\hline & TP3 & 0.64 & & & \\
\hline \multirow[t]{3}{*}{ Interaction expansion } & IE1 & 0.74 & 0.798 & 0.5757 & 0.8005 \\
\hline & IE2 & 0.65 & & & \\
\hline & IE3 & 0.87 & & & \\
\hline \multirow[t]{3}{*}{ Course content fit } & CCF1 & 0.63 & 0.780 & 0.55 & 0.7835 \\
\hline & $\mathrm{CCF} 2$ & 0.74 & & & \\
\hline & CCF3 & 0.84 & & & \\
\hline \multirow[t]{3}{*}{ Information richness } & IR1 & 0.72 & 0.790 & 0.5658 & 0.7953 \\
\hline & IR2 & 0.70 & & & \\
\hline & IR3 & 0.83 & & & \\
\hline \multirow[t]{3}{*}{ Students' satisfaction } & SAT1 & 0.57 & 0.744 & 0.5211 & 0.7612 \\
\hline & SAT2 & 0.73 & & & \\
\hline & SAT3 & 0.84 & & & \\
\hline \multirow[t]{3}{*}{ Perceived value } & PV1 & 0.60 & 0.765 & 0.5457 & 0.7771 \\
\hline & PV2 & 0.91 & & & \\
\hline & PV3 & 0.67 & & & \\
\hline \multirow[t]{3}{*}{ Users' continuance intention } & CI1 & 0.77 & 0.760 & 0.5244 & 0.7674 \\
\hline & $\mathrm{CI} 2$ & 0.69 & & & \\
\hline & $\mathrm{CI} 3$ & 0.71 & & & \\
\hline
\end{tabular}


All Cronbach's $\alpha$ and composite reliability values are above thresholds of 0.7 (Nunnally et al. 1967). All the factor loadings from the CFA exceeded the threshold value of 0.50 (Peterson 2000), which suggested good convergent validity for the corresponding constructs. Accordingly, a good degree of reliability and validity of all constructs was validated and the data can be used for further test.

Test on measurement model and second-order factor model for pedagogical MSNS perception

LISREL 8.80 is used to test the models. Goodness-of-fit for the two models are listed in Table 2; data reveal that the two models are both acceptable and fit indexes of the measurement model are a little bit better than those of the second-order factor model. Hence, the measurement model is fit for measuring users' perception and the secondorder factor model is fit for simplifying a research model when users' perception is taken as a variable in a full model. Usually, the approach of item parceling is combined with second-order factor model to make the simplification.

Consequently, based on the analysis of the two models, the second-order factor model is adopted and the perceived quality of an MSNS is introduced into the research model as a latent variable.

Test on research model and hypotheses

The goodness-of-fit and results are listed in Table 3, indicating that all indices are acceptable.

Figure 4 shows the model testing results. There are five sub-constructs under perceived quality of a MSNS use in u-learning, which are distinctive characteristics of the innovative pedagogy. With acceptable goodness-in-fit, average values of all scale items to corresponding sub-constructs are taken as reflective items for the higher-order factor-perceived quality, with factor loadings shown in Fig. 4.

Factor loadings of Information Richness, Teacher's Participation, Interaction Expansion, Course Content Fit, and Perceived Convenient Function on MSNS perceived quality were all above the threshold value of 0.50 (Peterson 2000) with

Table 2 Goodness-of-fit for the measurement model and second-order model of MSNS perception

\begin{tabular}{lccl}
\hline Fit index & $\begin{array}{l}\text { Values of } \\
\text { measurement model }\end{array}$ & $\begin{array}{l}\text { Values of second- } \\
\text { order factor model }\end{array}$ & Criterion \\
\hline$X^{2}(\mathrm{~d} f)$ & $150.18(80)$ & $178.70(85)$ & The less the better \\
$X^{2} / \mathrm{d} f$ & 1.877 & 2.102 & $\begin{array}{c}\text { The less the better, } \\
\text { lower than 5 is acceptable }\end{array}$ \\
RMSEA & 0.066 & 0.074 & $<0.1$ \\
NFI & 0.97 & 0.96 & $>0.9$ \\
NNFI & 0.98 & 0.98 & $>0.9$ \\
CFI & 0.99 & 0.98 & $>0.9$ \\
SRMR & 0.044 & 0.049 & $<0.08$ \\
\hline
\end{tabular}


Table 3 Goodness-of-fit for the structural model

\begin{tabular}{lll}
\hline Fit index & Value & Criterion \\
\hline$X^{2}(\mathrm{~d} f)$ & $115.57(72)$ & The less the better \\
$X^{2} / \mathrm{d} f$ & 1.605 & The less the better, lower than 5 is acceptable \\
RMSEA & 0.055 & $<0.1$ \\
NFI & 0.95 & $>0.9$ \\
NNFI & 0.98 & $>0.9$ \\
CFI & 0.98 & $>0.9$ \\
SRMR & 0.056 & $<0.08$ \\
\hline
\end{tabular}

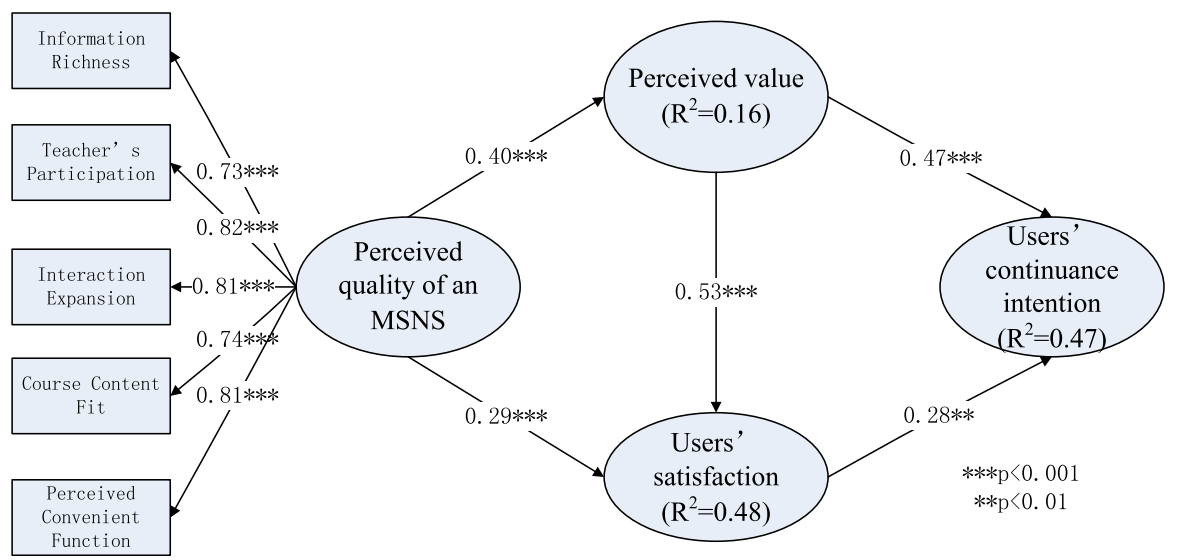

Fig. 4 The research model

Table 4 Summary of hypotheses tests

\begin{tabular}{lllll}
\hline No. & Hypothesis & $\beta$ & Support & Significance level \\
\hline 1 & Perceived quality of an MSNS $\rightarrow$ Perceived value & 0.40 & Yes & $p<0.001$ \\
2 & Perceived quality of an MSNS $\rightarrow$ Users' satisfaction & 0.29 & Yes & $p<0.001$ \\
3 & Perceived vaule $\rightarrow$ Users' satisfaction & 0.53 & Yes & $p<0.001$ \\
4 & Perceived vale $\rightarrow$ Users' continuance intention & 0.47 & Yes & $p<0.001$ \\
5 & Users' satisfaction $\rightarrow$ Users' continuance intention & 0.28 & Yes & $p<0.01$ \\
\hline
\end{tabular}

significance level of $p<0.001$. Teacher's Participation bore the highest factor loading among the five and Information Richness was the lowest.

Summary of hypotheses tests are listed in Table 4.

The five hypotheses presented were tested collectively using the SEM approach with the maximum likelihood technique. The four indicators were modeled in a reflective manner, and the factor loadings of the five to the perceived quality of an 
MSNS was depicted on the figure because they were after simplification and were factors affecting users' perception.

All five hypothesized paths in the model were significant. Users' continuance intention was predicted by satisfaction $(\beta=0.28)$ and perceived value $(\beta=0.47)$, which explained $47 \%$ of the intention variance totally. In addition to its direct effect, perceived value also had an indirect effect on users' continuance intention $(\beta=0.15)$ via users' satisfaction construct. Users' satisfaction, in turn, was predicted by perceived quality of an MSNS $(\beta=0.29)$ and perceived value $(\beta=0.53)$, which explained $48 \%$ of the satisfaction variance totally. Perceived quality of an MSNS also had an indirect effect $(\beta=0.21)$ on users' satisfaction, via the perceived value construct. Finally, perceived quality of an MSNS was a significant predictor of perceived value $(\beta=0.40)$, explaining $16 \%$ of the perceived value variance. Further discussion on implications of these effects for users' continuance intention is in the next section.

\section{Discussion and conclusions}

Implications for theory and research

Following the framework of "cognition-affect-conation", the study theorized perceived quality of an MSNS, perceived value, and users' satisfaction as independent variables, users' continuance intention as dependant variable into a behavioral model to investigate students' continuance use behavior on MSNS-base pedagogical tool.

Firstly, the structural model on perceived quality of MSNS-based u-learning was constructed and validated, which reveals that the perceived quality is the one with multiple constructs, including perceived convenient function, information richness, interaction expansion, course content fit, and teachers' participation. All the five give their contributions to the quality perception of MSNS-based u-learning. Particularly, these factors are extracted from the context of a MSNS-based pedagogy utilizing, which are seldom studied in existing literatures.

Secondly, a higher-order factor for the perceived quality of a MSNS-based pedagogy is validated, indicating that a measurement model with multiple constructs can be simplified into one factor to quality perception. As a rigorous research, a reliable validation is necessary before the model simplification, which is neglected in some previous studies. We provide an approach for the behavioral model simplification in the situation of multiple constructs for one factor, which is benefit for the clarification of casual relations.

Thirdly, "cognition-affect-conation" framework was examined as effective to explain users' continuance behavior in the context of utilizing a MSNS as u-learning tool. In specific, users' perception on a MSNS-based pedagogical tool is the stage of cognition construction; users' satisfaction and perceived value on the tool is the psychological response to the utilizing of a MSNS, which is the stage of affect formation. Users' continuance intention is the stage of conation, which will impact users' actual behavior of continue use. 
Fourthly, according to the results of data analysis, users' continuance intention is affected by perceived quality of a MSNS, but it is mediated by perceived value and users' satisfaction. The relation between users' satisfaction and perceived quality is mediated by perceived value, and users' satisfaction also mediates the effect of perceived value on users' continuance intention. These relations clarify the mechanism of users' continuance intention based on the mode "cognition-affectconation" in explaining students' behavior of utilizing MSNS-based pedagogical tools.

The last, although the results of hypotheses tests are similar to existing literatures (Bhattacherjee 2001; Chiu et al. 2005; Kettinger et al. 2009; Limayem and Cheung 2008; Lin and Wang 2012; Ng and Kwahk 2010), there were still differences found in the study. The analysis indicates that in the context of MSNSbased u-learning, perceived quality on an MSNS puts less effect on perceived value than that of users' satisfaction, but the effect of perceived value on users' continuance intention is bigger than that of users' satisfaction. It delivers the implication that perceived value impacts users' behavior well in MSNS-base ulearning.

\section{Practical contribution}

MSNS is introduced into u-learning as a pedagogical tool, which is an innovation different from the use of e-learning systems. The analysis shows that teachers' participation has the highest loading, which indicates that teachers' role should be considered well in the MSNS-based pedagogy design.

Mobile access and open interactions are its distinctive characteristics. Interaction expansion and perceived convenient function posses high loadings, they reflect students' perception on characteristics of social interaction and mobile access. Accordingly, teachers using MSNS as their pedagogical tools should put efforts on how to develop advantages of mobile access and social interactions to improve students' learning performance.

Information richness and course content fit bear the lower but significant loadings to perceived quality. On the one hand, there is massive information on each MSNS, so it is not a surprise that information richness is significant, but it is not as high as expected, the possible reason is that there is too much information, sometimes even cause information overloading to students. On the other hand, the content fitting to courses, compared with content of social life, is not sufficient. Consequently, suggestions for pedagogical designers are providing help for retrieving useful information and putting efforts on building mini course content for swift leaning on MSNS.

\section{Limitations and future research suggestions}

The study suffers limitations as follows: First, the results are based on the data from the use of Weibo, different MSNSs have different characteristics, hence, generalizing the results to other kind of MSNS (e.g., Wechat, Facebook, Renren, etc.) in 
pedagogy should be handled carefully. Second, the context studied is computer courses learning, which are ICT related ones, the situation in other courses, especially those do not have close relation to ICT, deserves further validation. Third, the survey conducted in this study is self-reported, which will lead possible bias between respondents' answer and their behavior. Accordingly, suggestions for future research includes: examining the model in different MSNSs and courses; adding control variables (e.g., gender, GPA, etc.) to the model to indicate subtle effects; conducting a longitudinal study to further explore users' behavior; investigating the effects of MSNS utilizing on students' learning performance.

Acknowledgments The authors wish to thank grant support from Ministry of Education of the People's Republic of China, Humanities and Social Sciences project (12YJC630209) and North China University of Technology, University Funds for Excellent Young Scholars (2014).

\section{Appendix}

See Table 5.

Table 5 Survey items

\begin{tabular}{|c|c|}
\hline Construct & Scale item \\
\hline $\begin{array}{l}\text { Perceived convenient } \\
\text { function }\end{array}$ & $\begin{array}{l}\text { PCF1. I can access Weibo very conveniently with my smart phone } \\
\text { PCF2. Functions provided by Weibo is very convenient for me to use } \\
\text { PCF3. Over all, Mobile Weibo is very convenient for use }\end{array}$ \\
\hline $\begin{array}{l}\text { Teachers", } \\
\text { participation }\end{array}$ & $\begin{array}{l}\text { TP1. My teacher often update his Weibo } \\
\text { TP2. My messages posted on Weibo, if related to learning issues, always } \\
\text { repklied by the teacher } \\
\text { TP3. The teacher often provides course learning realted materials on the Weibo }\end{array}$ \\
\hline Interaction expansion & $\begin{array}{l}\text { IE1. By using Weibo, I have good chance to interact with others not just limited } \\
\text { to my classmates } \\
\text { IE2. With Weibo utilizing, I can interact with others at any time and anywhere, } \\
\text { not just limitted in the classroom } \\
\text { IE3. Over all, using Weibo can substantially expand my interactions }\end{array}$ \\
\hline Course content fit & $\begin{array}{l}\text { CCF1. I can often get materials related to my current learning course content } \\
\text { from groups interested in computer technology } \\
\text { CCF2. I can often get materials related to my current learning course content } \\
\text { from my fans on Weibo } \\
\text { CCF3. Over all, I can often get materials fitting for my current learning course } \\
\text { content }\end{array}$ \\
\hline Information richness & $\begin{array}{l}\text { IR1. There is massive information related all kinds of social life on Weibo } \\
\text { IR2. There is massive information fitting for different interest on Weibo } \\
\text { IR3. Over all, Weibo can provide massive information }\end{array}$ \\
\hline
\end{tabular}


Table 5 continued

\begin{tabular}{ll}
\hline Construct & Scale item \\
\hline Students' satisfaction & I am $\begin{array}{l}\text { Extremely displeased...... Extremely pleased } \\
\text { SAT2. Extremely frustrated.......Extremely contented }\end{array}$ \\
& SAT3. Extremely dissatisfied......Extremely satisfied \\
Perceived value & PV1. For the time and effort I spend, the use of the Weibo in my current learning \\
& is worthwhile \\
& PV2. Compared to what I had spent on time and effort, using Weibo as a learing \\
& tool is very valuable \\
& PV3. Overall, the value of utilizing Weibo in my learning activities is very high \\
Users' continuance & CI1. If I could, I would like to continue using Weibo in my learning activities in \\
intention & the future \\
& CI2. It is likely that I will continue using Weibo as a tool for learning in the \\
future & CI3. I intend to continue using Weibo as a tool for learning rather than \\
discontinue its use
\end{tabular}

\section{References}

Bagozzi, R. P. (1992). The self-regulation of attitudes, intentions, and behavior. Social Psychology Quarterly, 55, 178-204.

Beach, A., Gartrell, M., Akkala, S., Elston, J., Kelley, J., Nishimoto, K., et al. (2008). Whoz that? Evolving an ecosystem for context-aware Mobile Social Networks. Network, IEEE, 22(4), 50-55.

Becker, A., Mladenow, A., Kryvinska, N., \& Strauss, C. (2012). Aggregated survey of sustainable business models for agile mobile service delivery platforms. Journal of Service Science Research, 4 (1), 97-121.

Bhattacherjee, A. (2001). Understanding information systems continuance: an expectation-confirmation model. MIS Quarterly, 25(3), 351-370.

Chang, C., Liang, C., Yan, C., \& Tseng, J. (2013a). The impact of college students' intrinsic and extrinsic motivation on continuance intention to use English Mobile Learning Systems. The Asia-Pacific Education Researcher, 22, 1-12.

Chang, C., Tseng, K., Liang, C., \& Yan, C. (2013b). The influence of perceived convenience and curiosity on continuance intention in mobile English learning for high school students using PDAs. Technology, Pedagogy and Education, 22(3), 373-386.

Chiu, C. M., Chiu, C. S., \& Chang, H. C. (2007). Examining the integrated influence of fairness and quality on learners' satisfaction and Web-based learning continuance intention. Information Systems Journal, 17(3), 271-287.

Chiu, C., Hsu, M., Sun, S., Lin, T., \& Sun, P. (2005). Usability, quality, value and e-learning continuance decisions. Computers \& Education, 45(4), 399-416.

Chiu, C., \& Wang, E. T. (2008). Understanding Web-based learning continuance intention: The role of subjective task value. Information \& Management, 45(3), 194-201.

Davis, F. D. (1989). Perceived usefulness, perceived ease of use, and user acceptance of information technology. MIS quarterly, 13, 319-340.

Ellison, N. B. (2007). Social network sites: Definition, history, and scholarship. Journal of ComputerMediated Communication, 13(1), 210-230.

Hwang, G., Hung, P., Chen, N., \& Liu, G. (2014). Mindtool-assisted in-field learning (MAIL): An advanced ubiquitous learning project in Taiwan. Journal of Educational Technology \& Society, 17 (2), 4-16.

Hwang, G., Tsai, C., \& Chen, C. Y. (2012). A context-aware ubiquitous learning approach to conducting scientific inquiry activities in a science park. Australasian Journal of Educational Technology, 28(5), 931-947. 
Hwang, G., Tsai, C., \& Yang, S. J. (2008). Criteria, strategies and research issues of context-aware ubiquitous learning. Educational Technology \& Society, 11(2), 81-91.

Kettinger, W. J., Park, S., \& Smith, J. (2009). Understanding the consequences of information systems service quality on IS service reuse. Information \& Management, 46(6), 335-341.

Lee, M. (2010). Explaining and predicting users' continuance intention toward e-learning: An extension of the expectation confirmation model. Computers \& Education, 54(2), 506-516.

Liang, T., Ling, Y., Yeh, Y., \& Lin, B. (2013). Contextual factors and continuance intention of mobile services. International Journal of Mobile Communications, 11(4), 313-329.

Limayem, M., \& Cheung, C. M. (2008). Understanding information systems continuance: The case of Internet-based learning technologies. Information \& Management, 45(4), 227-232.

Lin, K. (2011). e-Learning continuance intention: Moderating effects of user e-learning experience. Computers \& Education, 56(2), 515-526.

Lin, K., Chen, N., \& Fang, K. (2011). Understanding e-learning continuance intention: a negative critical incidents perspective. Behaviour \& Information Technology, 30(1), 77-89.

Lin, W., \& Wang, C. (2012). Antecedences to continued intentions of adopting e-learning system in blended learning instruction: A contingency framework based on models of information system success and task-technology fit. Computers \& Education, 58(1), 88-99.

Liu, Y., Li, H., \& Carlsson, C. (2010). Factors driving the adoption of m-learning: An empirical study. Computers \& Education, 55(3), 1211-1219.

Lu, H. P., \& Chiou, M. J. (2010). The impact of individual differences on e-learning system satisfaction: A contingency approach. British Journal of Educational Technology, 41(2), 307-323.

Ng, E. H., \& Kwahk, K. (2010). Examining the determinants of Mobile Internet service continuance: a customer relationship development perspective. International Journal of Mobile Communications, 8 (2), 210-229.

Nunnally, J. C., Bernstein, I. H., \& Berge, J. M. T. (1967). Psychometric theory. New York: McGraw-Hill.

Ogata, H., Li, M., Hou, B., Uosaki, N., El-Bishouty, M. M., \& Yano, Y. (2011). SCROLL: Supporting to share and reuse ubiquitous learning log in the context of language learning. Research and Practice in Technology Enhanced Learning, 6(2), 69-82.

Oliver, R. L. (2010). Satisfaction: A behavioral perspective on the consumer. New York: ME Sharpe.

Parasuraman, A., Zeithaml, V. A., \& Berry, L. L. (1988). Servqual. Journal of Retailing, 64(1), 12-40.

Peterson, R. A. (2000). A meta-analysis of variance accounted for and factor loadings in exploratory factor analysis. Marketing Letters, 11(3), 261-275.

Shin, D., Shin, Y., Choo, H., \& Beom, K. (2011). Smartphones as smart pedagogical tools: Implications for smartphones as u-learning devices. Computers in Human Behavior, 27(6), 2207-2214.

Terzis, V., Moridis, C. N., \& Economides, A. A. (2013). Continuance acceptance of computer based assessment through the integration of user's expectations and perceptions. Computers \& Education, 62, 50-61.

Venkatesh, V., Thong, J. Y., Chan, F. K., Hu, P. J. H., \& Brown, S. A. (2011). Extending the two-stage information systems continuance model: Incorporating UTAUT predictors and the role of context. Information Systems Journal, 21(6), 527-555.

Wang, R., Liu, K., Zhijun, Y., \& Wang, Q. (2014). Simplification and application of structural equation model in human computers behavioral research (in Chinese). Mathematics in Practice and Theory, 44(3), 92-99.

Zhao, L., Lu, Y., Zhang, L., \& Chau, P. Y. (2012). Assessing the effects of service quality and justice on customer satisfaction and the continuance intention of mobile value-added services: An empirical test of a multidimensional model. Decision Support Systems, 52(3), 645-656.

Ruobin Wang received his Ph.D. from Beijing Institute of Technology, Beijing, China. Currently, he is an instructor at North China University of Technology, Beijing, China. Dr. Wang's research interests include behavioral issues in e-learning, ubiquitous and mobile learning, adaptivity and personalization, and artificial intelligence.

Chuntao Du is associate professor at School of Computer Science, North China University of Technology, Beijing, China. Dr. Du's research interests include web-based learning, ubiquitous and mobile learning, e-learning systems, and software engineering. 